Open Access

\title{
Effect of early and current Helicobacter pylori infection on the risk of anaemia in 6.5-year-old Ethiopian children
}

Bineyam Taye ${ }^{1,2^{*}}$, Fikre Enquselassie ${ }^{1}$, Aster Tsegaye ${ }^{2}$, Alemayehu Amberbir ${ }^{3}$, Girmay Medhin ${ }^{4}$, Andrew Fogarty ${ }^{5}$, Karen Robinson ${ }^{6}$ and Gail Davey ${ }^{7}$

\begin{abstract}
Background: Epidemiological and clinical studies in high income countries have suggested that Helicobacter pylori (H. pylori) may cause anaemia, but evidence is lacking from low income countries.We examined associations between $\mathrm{H}$. pylori infection in early childhood and anaemia at the age of 6.5 years in an Ethiopian birth cohort.

Methods: In 2011/12, 856 children (85.1\% of the 1006 original singletons in a population-based birth cohort) were followed up at age six and half. An interviewer-led questionnaire administered to mothers provided information on demographic and lifestyle variables. Haemoglobin level and red cell indices were examined using an automated haematological analyzer (Cell Dyn 1800, Abbott, USA), and stool samples analyzed for H. pylori antigen. The independent effects of $\mathrm{H}$. pylori infection (measured at age 3.5 and 6.5 years) on anaemia, haemoglobin level, and red cell indices (measured at age 6.5 years) were determined using multiple logistic and linear regression.

Results: The prevalence of anemia was $34.8 \%$ (257/739), and the mean (SD) haemoglobin concentration was $11.8(1.1) \mathrm{gm} / \mathrm{dl}$. Current H. pylori infection at age 6.5 years was positively, though not significantly related to prevalence of anaemia (adjusted $\mathrm{OR}, 95 \% \mathrm{Cl}, 1.15 ; 0.69,1.93, \mathrm{p}=0.59$ ). Any $\mathrm{H}$. pylori infection up to age 6.5 years was significantly associated with an increased risk of anaemia at age 6.5 (adjusted $\mathrm{OR}, 95 \% \mathrm{Cl}, 1.68 ; 1.22,2.32, \mathrm{p}=0.01$ ). A significant reduction in haemoglobin concentration and red cell indices was also observed among children who had any H. pylori infection up to age 6.5 ( $\mathrm{Hb}$ adjusted $\beta=-0.19,95 \% \mathrm{Cl},-0.35$ to $-0.03, p=0.01$; MCV adjusted $\beta=-2.22$, $95 \% \mathrm{Cl},-3.43$ to $-1.01, \mathrm{p}=0.01$; $\mathrm{MCH}$ adjusted $\beta=-0.63,95 \% \mathrm{Cl},-1.15$ to $-0.12, \mathrm{p}=0.01$; and $\mathrm{MCHC}$ adjusted $\beta=-0.67,95 \% \mathrm{Cl},-1.21$ to $-0.14, p=0.01$ ), respectively.
\end{abstract}

Conclusion: This study provides further evidence from a low income country that any H. pylori infection up to age 6.5 is associated with higher prevalence of anaemia, and reduction of haemoglobin level and red cell indices at age 6.5.

Keywords: Helicobacter pylori, Anaemia, Red cell indices, Birth cohort, Ethiopia

\footnotetext{
* Correspondence: bineymt@gmail.com

'School of Public Health, College of Health Sciences, Addis Ababa University,

PO Box 80596, Addis Ababa, Ethiopia

${ }^{2}$ School of Allied Health Sciences, College of Health Sciences, Addis Ababa

University, Addis Ababa, Ethiopia

Full list of author information is available at the end of the article
} 


\section{Background}

Helicobacter pylori (H. pylori), a spiral-shaped pathogenic bacterium found on the human gastric mucosa, was first isolated by Warren and Marshall in 1982 [1]. The bacterium is a ubiquitous micro-organism, infecting half of the world's population [2] and is widely accepted as the main etiological factor for peptic ulcer disease and gastric malignancy $[3,4]$. The infection is usually acquired in childhood and persists throughout life, causing disease mainly in adults $[5,6]$. In children, however, the consequences of $H$. pylori infection in gastroduodenal diseases are not well understood [7]; the majority have no specific symptoms $[8,9]$ and peptic ulcer disease is relatively rare in childhood [10]. More recently however, there is growing interest in investigating the effects of $H$. pylori in extra-gastroduodenal diseases $[8,11]$. In particular, evidence for an association between $H$. pylori and anaemia has gained support from a range of epidemiological studies [12-15]. Moreover, improvement in iron deficiency anaemia (IDA) after $H$. pylori eradication has been demonstrated in children and adults with unexplained IDA [16-18].

The mechanisms by which $H$. pylori infection can cause iron deficiency anaemia are still unclear [19], but plausible mechanisms have been proposed. One hypothesis that has attracted attention is that chronic $H$. pylori infection leads to atrophy of the gastric glands and reduction of gastric hydrochloric and ascorbic acid secretion [20]. This in turn leads to increases in intragastric $\mathrm{pH}$, which may impair iron absorption [21]. Other possible mechanisms for IDA in $H$. pylori-infected subjects involve altered expression of iron transport regulators, and uptake of iron by $H$. pylori bacteria in the gastric mucosa $[22,23]$. Lactoferrin is an iron-binding glycoprotein that is found in body fluids, and its secretion in the gastric mucosa seems to be influenced by some signal from $H$. pylori [22]. It appears that $H$. pylori then absorbs the iron from lactoferrin via a specific lactoferrin-binding protein that is expressed by H. pylori [20]. Lactoferrin levels in the gastric mucosa have been shown to be significantly higher in $H$. pylori-positive patients with IDA than those who are non-anaemic $H$. pylori-negative, nonanaemic $H$. pylori-positive, and $H$. pylori-negative with IDA [22].

Whilst there is a growing body of epidemiological evidence suggesting that $H$. pylori infection is associated with an increased risk of anaemia and iron deficiency, most studies to date are in adult high-income country populations and lack data in children from low income countries, though $H$. pylori is a very common bacterial infection, infecting more than $50 \%$ of children in low income countries [24, 25].

In low income countries, well-documented causes of anaemia in children include dietary iron deficiency, vitamin A deficiency, and infectious diseases such as malaria and hookworm [26], but the potential role of H. pylori infections in childhood anaemia has not been investigated. In low income settings, it may be difficult to exclude other potential causes of childhood anaemia. However, in the Butajira area of southern Ethiopia, where this study cohort is situated, the magnitude of intestinal parasitosis is very low among 3 years old children [27], and malaria transmission is low [28].

We therefore used data from our Ethiopian Birth cohort to assess the association between child's exposure to $H$. pylori infection (measured at age 3, 5, and 6.5 years) and prevalence of anaemia at age 6.5 years. We also tested whether $H$. pylori infection was associated with mean difference in haemoglobin and red cell indices at age 6.5 years. Our group have previously reported $H$. pylori prevalence data age 3 and age 5 [27, 29]. For the current study, additional data were gathered at age 6.5 years.

\section{Methods}

\section{Study setting and design}

A detailed description of the original Butajira birth cohort study has been published [27, 30]. Briefly, the birth cohort is nested in the Butajira Demographic Surveillance Site (DSS) which covers a sample of nine rural and one urban administrative units in and around the town of Butajira in Southern Ethiopia [31]. Between July 2005 and February 2006, all women in the DSS aged 15-49 and in their third trimester of pregnancy were identified by the DSS fieldworkers and invited to participate in the study. Of the 1,234 eligible women, 1,065 were recruited ( $86 \%$ of those eligible) and all live singleton babies born to these women $(n=1006)$ were followed-up as a birth cohort.

\section{Measurement and data collection}

After informed consent forms were signed by the mothers, information on demographic and selected lifestyle factors was collected by interviewer-led administered questionnaire during pregnancy: information on mother's age, place of residence, ethnicity, religion, occupation, education and household income was collected. At birth and during the follow-up visits, the project data collectors visited the child at home and collected information on potential confounders such as birth weight, history of vaccination, household size, vitamin A supplementation, intestinal parasitosis, anthropometric characteristics and sanitary conditions.

At follow up visits at ages 3, 5 and 6.5 years, mothers were also asked to collect a faecal sample from their child using a leak-proof plastic container. The samples were then transported for analysis in the Butajira health center laboratory to ascertain the child's $H$. pylori and intestinal parasites infection status. Furthermore, at the 
6.5 year follow up visit, a blood sample was collected from each child using a vacutainer tube, and transported to Butajira hospital for haematological analysis.

\section{Laboratory analyses}

H. pylori status was evaluated using the commercially available SD Bioline H. pylori stool antigen test (Standard Diagnostics, Inc) according to the manufacturer's instructions. A portion of faeces (about $50 \mathrm{mg}$ ) from a stool sample was swirled with assay diluent solution at least for ten times, until the sample has been dissolved, and then allowed to settle for $5 \mathrm{~min}$ at room temperature. About $100 \mu \mathrm{L}$ of the prepared sample was placed on the H. pylori $\mathrm{Ag}$ examination device. The test results were checked about $15 \mathrm{~min}$ later. One red line indicated negative and a double red line indicated an $H$. pylori positive result.

Additionally, all faecal samples were examined qualitatively using the modified formol-ether concentration method to ascertain the child's intestinal parasites infection status.

\section{Haematological analysis}

At the 6.5-year follow-up, a two ml whole blood sample was collected into Ethylene diaminetetraacetic acid (EDTA) tubes between 8:00 and 10:00 am and analyzed on the same day using an automated haematological analyzer (Cell Dyn 1800, Abbott, USA) at Butajira hospital. The analyzer aspirates the blood sample, dilutes and counts leukocytes, erythrocytes and thrombocytes, measures Mean Cell Volume (MCV) and Haemoglobin (Hb), and calculates Haematocrit, Mean Cell Haemoglobin $(\mathrm{MCH})$, and Mean Cell Haemoglobin Concentration (MCHC). This instrument was monitored daily with normal, high and low controls provided by the manufacturer before running the specimen to ensure quality of haematological analyses.

\section{Outcome definition}

The primary study outcome was anaemia at age 6.5, and was defined according to the WHO hemoglobin cutoff: < $11.5 \mathrm{~g} / \mathrm{dL}$ for children 5-11 years [32].

\section{Statistical analysis}

Data were double-entered into EpiData 3.1 (EpiData, Denmark). The datasets were cleaned, coded and merged ready for analysis using Stata 12 (Statacorp, College Station, Texas, USA).

Prior to investigating the association between $H$. pylori infection and anaemia, univariate analyses were used to identify the possible confounders. Variables that were associated with both exposure and outcome variables in the crude analysis using statistical significance at $p$ value $<0.2$ were considered to be possible confounders. These included place of residence, ethnicity, religion, maternal education, source of water, crowdedness, sanitary conditions, history of vaccination and history of vitamin A supplementation. Additionally, we included variables previously shown to be associated with anaemia in the literature; child's sex, anthropometric measures of nutritional status and intestinal parasite status [33].

The hypothesis that infection with $H$. pylori would be associated with anaemia (a categorical variable) was assessed using univariate and multivariate logistic regression models. To evaluate the effect of $H$. pylori on haemoglobin and red cell indices as continuous outcomes $(Y)$, regression analyses were performed using generalized linear models (GLIM) with random response variables, $\mathrm{Hb}, \mathrm{RBC}, \mathrm{MCV}, \mathrm{MCH}$ and $\mathrm{MCHC}$ assuming a gamma distribution for $Y$. Maximum likelihood allowed estimation of column vector of coefficients, $\beta$, in the function $f(\mu Y)=\mathrm{X} \beta$, where $f()$ is the link function. We chose the logarithm link $(\log (\mu Y)=\mathrm{X} \beta)$, based on the optimization of both the Akaike Information Criterion and the Bayesian Information Criterion [34].

We first examined the crude association between child's $H$. pylori infection (measured at age 3, 5, 6.5 years) and outcome variables (anaemia, haemoglobin and red cell indices) at age 6.5 years. We then repeated the analysis, adjusting for the possible confounders and predictors of outcome listed in Additional file 1: Table S1.

The same approach was used in a separate set of analyses to assess the association between $H$. pylori infection and anaemia, haemoglobin level and red cell indices for all available children at year 6.5 , by creating a new exposure variable with categories representing different combinations of $H$. pylori exposure status at age 3, 5 and 6.5: 'never infected' (never infected at any of these three time points) and 'infected any age up to year 6.5'. Covariates were kept in the model if they changed the coefficient of exposure (H. pylori infection) by $>10 \%$ or if they were independently associated with the outcome at $p<0.10$. Probability values $<0.05$ were considered statistically significant for main effects. Sensitivity analysis was done to compare the distribution of demographic and life style variables between study subject who have complete outcome data (i.e. "complete-case") and "all respondents" populations.

\section{Ethical approval}

The study was approved by the Institutional Review Board (IRB) of Addis Ababa University, College of Health Sciences, Ethiopia. Written, informed consent was obtained from the mothers after they have been clearly informed about the study, and in keeping with the requirements of the College of Health Sciences IRB all women and their children were reimbursed for health care costs. Children were also requested to give assent and were informed of their right to refuse to participate 
in the study and to withdraw at any time during the study without jeopardizing their right of access to other health services. Invasive procedures such as collection of blood samples were fully explained to parents and children, and were carried out using sterile disposable materials.

\section{Results \\ Description of cohort participants followed-up at age 6.5 years}

At recruitment, a total of 1,006 singleton babies made up the initial birth cohort, of which 64 (6.4\%) had died and $10(0.9 \%)$ had migrated from the study area before their first birthday. A detailed description of the cohort at years 1,3 , and 5 is reported elsewhere [27, 29, 31]. At 6.5 years, a total of 856 singleton children were successfully followed-up ( $85.1 \%$ of the original cohort at birth, and $99.3 \%$ of those available at year 5 follow-up), of whom 739 had haematology and 848 had H. pylori data at the 6.5 year follow up visit (Fig. 1). Comparing the distribution of demographic and life style variables between study subjects who have complete outcome data (i.e. "complete-case" and "all respondents"), found similar patterns of distribution in relation to demographic and life style characteristics (Additional file 2: Table S3).

\section{Selected demographic and lifestyle characteristics of children and their mothers at the 6.5 year follow-up visit} Of children enrolled at the 6.5 year follow up visit, $51.2 \%(434 / 848)$ were male and the majority, $88.2 \%$ $(748 / 848)$ were from a rural area. Maternal demographic characteristics showed that $47.4 \%(402 / 848)$ of the mothers belonged to the Meskan ethnic group, $78.4 \%$ (665/848) were Muslim, $71.6 \%$ (607/848) were illiterate and $83.8 \%$ were housewives (709/848). Most mothers $(61.3 \%, 520 / 848)$ reported using piped water as their primary drinking source. Selected early life characteristics at 2 months and 1 year of age showed that $57.5 \%$ had been vaccinated at 2 months and only 11.7 (99/848) had received vitamin A supplementation at 1 year. Only $60 \%$ of children had birth weight data, and of these, $91.3 \%(483 / 529)$ were of normal birth weight (Table 1$)$.

\section{Anaemia and haematology parameters among children followed up at age 6.5}

The prevalence of anaemia among children enrolled at the 6.5 year follow up visit was $34.8 \%$ (257/739), and the mean (SD) hematological parameters were: haemoglobin concentration 11.8 (1.1) gm/dl; red blood cells $4.5(0.37) \times 10^{12} / \mathrm{L}$; mean cell haemoglobin $26.1(2.2) \mathrm{pg}$; mean cell haemoglobin concentration 31.6 (1.5) gm/dl; mean cell volume 81.1 (4.8) fl. No significant differences in haematological parameters between males and females were observed. Likewise, the prevalence of anaemia did not differ significantly between sexes, (33.0\% vs $36.5 \%$ in female and males, respectively, $\mathrm{p}=0.31$, Table 2 ).

Prevalence of $H$. pylori infection at age 3, 5 and 6.5 years $H$. pylori infection was reported in $41 \%$ of children at age three [27] and $44 \%$ at age five [29] respectively. However a sharp declining of $H$. pylori infection $10.4 \%$ $(88 / 848)$ was found at age 6.5 years. The prevalence of H. pylori infection at age 6.5 was significantly differ by urban or rural area of residence such that $17 \%(17 / 100)$ of urban children and $9.5 \%(71 / 748)$ of rural children have current infection $(\mathrm{p}<0.01)$ (Additional file 1: Table S1).

\section{Relation between potential confounders with anaemia and $H$. pylori infection}

Effects of potential confounders on outcomes and exposures showed no statistically significant association with most demographic and lifestyle variables including; child's sex, religion, history of vaccination, birth weight, history of vitamin A supplementation at 1 year, history of vaccination at 2 months, sanitary conditions, crowdedness or intestinal parasite infection at age 6.5. However, both $H$. pylori exposure at age 6.5 and $H$. pylori exposure at any age up to 6.5 were significantly associated with place of residence, while, anaemia was significantly associated with place of residence, source of water, maternal education and ethnic group (Additional file 1: Table S1).

\section{Association between $H$. pylori infection and Anaemia at age 6.5}

At the 6.5 year follow up visit, univariate analysis showed that the prevalence of anemia was higher in children infected with $H$. pylori $(37.0 \%)$ than in those not infected (34.5\%), but the difference was not significant $(\mathrm{p}=0.38)$. Children who had exposure to $H$. pylori infection at ages 3 and 5 were found to have higher prevalence of anaemia at age 6.5, and the latter association reached statistical significance $(\mathrm{p}<0.05)$. Furthermore, any $H$. pylori infection between 3 and 6.5 years of age was associated with a higher prevalence of anaemia at age 6.5 years (Additional file 3: Table S2).

In multivariate analysis adjusted for a priori confounders, $H$. pylori infection at ages 3 and 6.5 was positively, though not significantly, related to prevalence of anaemia at age 6.5 years (adjusted OR, $95 \% \mathrm{CI}, 1.16$; 0.79 to $1.71, \mathrm{p}=0.44$ and $1.15 ; 0.69$ to $1.93, \mathrm{p}=0.59$ respectively). There was an increased odds of anaemia at age 6.5 years given $H$. pylori infection at age 5 (adjusted OR, $95 \%$ CI, 1.52 ; 1.11 to $2.08, \mathrm{p}=0.01$, Table 3). Furthermore, separate analysis considering any $H$. pylori infection up to age 6.5 showed that increased odds of anaemia among children ever infected with $H$. pylori (adjusted OR, $95 \% \mathrm{CI}, 1.68 ; 1.22$ to $2.32, \mathrm{p}=0.01$, Table 3). 


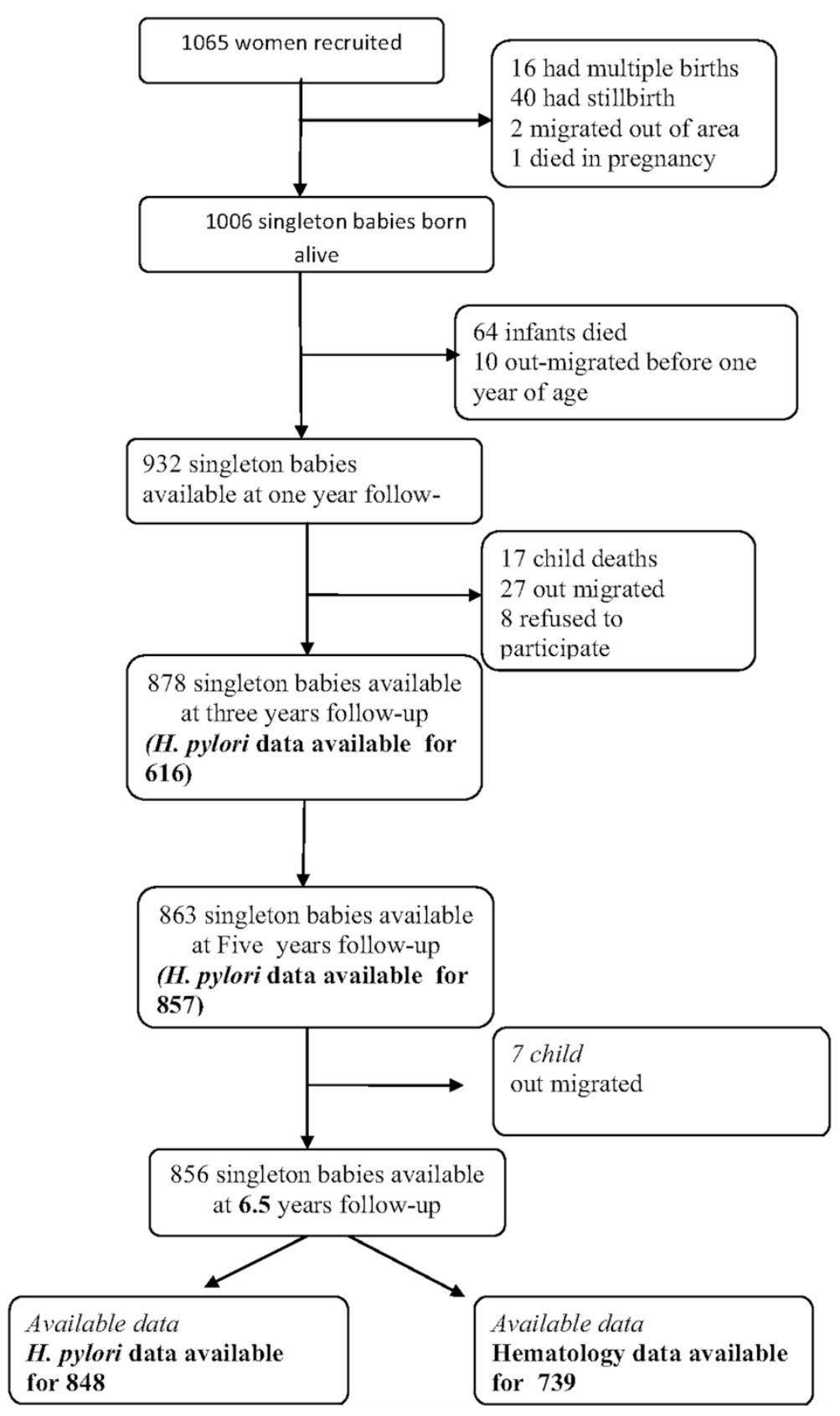

Fig. 1 The study cohort

\section{Association between $H$. pylori infection and haemoglobin level at age 6.5}

Linear regression models related haemoglobin concentration (outcomes) to the individual estimates of $H$. pylori infection status at ages 3, 5 and 6.5 years (exposures). These showed a non-significant reduction in haemoglobin concentration for children infected with $H$. pylori at age 6.5 compared to non infected children (adjusted $\beta=-0.08$; $95 \% \mathrm{CI},-0.34$ to $0.17, \mathrm{p}=0.52$ ), whilst the same analysis for children infected at age 5 showed a statistically significant reduction in haemoglobin concentration (adjusted $\beta=-0.20,95 \% \mathrm{CI} ;-0.37$ to $-0.04, \mathrm{p}<0.01)$. When haemoglobin concentrations among all children followed up to age 6.5 years were regressed against any $H$. pylori infection up to age 6.5 , being infected was associated with a significantly lower haemoglobin concentration (adjusted $\beta=-0.19,95 \% \mathrm{CI},-0.35$ to $-0.03, \mathrm{p}=0.01$, Table 4 ).

\section{Association between $H$. pylori infection and red cell indices at age 6.5}

Separate linear regression models related red cell indices (outcomes) to the individual estimates of $H$. pylori 
Table 1 Selected demographic and lifestyle characteristics of children and their mothers at 6.5 year follow-up visit, Butajira Birth Cohort, Ethiopia

\begin{tabular}{|c|c|c|}
\hline Variables & Number & Percen \\
\hline \multicolumn{3}{|l|}{ Sex } \\
\hline Male & 434 & 51.2 \\
\hline Female & 414 & 48.8 \\
\hline \multicolumn{3}{|l|}{ Place of residence } \\
\hline Urban & 100 & 11.8 \\
\hline Rural & 748 & 88.2 \\
\hline \multicolumn{3}{|l|}{ Ethnicity } \\
\hline Meskan & 402 & 47.4 \\
\hline Mareko & 111 & 13.1 \\
\hline Silti & 200 & 23.6 \\
\hline Others & 135 & 15.9 \\
\hline \multicolumn{3}{|l|}{ Religion } \\
\hline Orthodox Christian & 121 & 14.3 \\
\hline Muslim & 665 & 78.4 \\
\hline Catholic & 10 & 1.2 \\
\hline Protestant & 52 & 6.1 \\
\hline Maternal age Mean (SD) & $27.1(6.27)$ & \\
\hline \multicolumn{3}{|l|}{ Maternal age group } \\
\hline $15-24$ & 316 & 37.3 \\
\hline $25-34$ & 134 & 41.7 \\
\hline $35-44$ & 133 & 15.7 \\
\hline \multicolumn{3}{|l|}{ Maternal education } \\
\hline None & 607 & 71.6 \\
\hline Informal only & 83 & 9.8 \\
\hline Formal & 158 & 18.6 \\
\hline \multicolumn{3}{|l|}{ Maternal occupation } \\
\hline Housewife & 709 & 83.8 \\
\hline Farming and related & 27 & 3.2 \\
\hline Trading and related & 96 & 11.3 \\
\hline Other & 14 & 1.7 \\
\hline \multicolumn{3}{|c|}{ History of vaccination at 2 months } \\
\hline Vaccinated & 485 & 57.5 \\
\hline Not vaccinated & 359 & 42.5 \\
\hline \multicolumn{3}{|l|}{ Birth weight $(N=529)$} \\
\hline Normal & 483 & 91.3 \\
\hline Low (<2.5 kg) & 46 & 8.7 \\
\hline \multicolumn{3}{|c|}{ History of any vaccination at 1 year } \\
\hline Had some vaccination & 823 & 97.6 \\
\hline Not vaccinated at all & 20 & 2.4 \\
\hline \multicolumn{3}{|l|}{ Sanitary conditions } \\
\hline Poor & 156 & 18.4 \\
\hline Good & 692 & 81.6 \\
\hline
\end{tabular}

Table 1 Selected demographic and lifestyle characteristics of children and their mothers at 6.5 year follow-up visit, Butajira Birth Cohort, Ethiopia (Continued)

\begin{tabular}{lll}
\hline Water source & & \\
River & 179 & 21.2 \\
Well & 134 & 15.8 \\
Pipe & 520 & 61.5 \\
Spring & 13 & 1.5 \\
Vitamin A supplementation at 12 months & & \\
Yes & 99 & 11.7 \\
No & 747 & 88.3 \\
\hline
\end{tabular}

infection status at ages 3, 5 and 6.5 years (exposures). These showed a non-significant reduction for most red cell indices measured at age 6.5 years among $H$. pylori infected children compared to non-infected children. When red cell indices among all children followed up to age 6.5 years were regressed against any $H$. pylori infection up to age 6.5 years, being infected was associated with lower red cell indices; MCV (adjusted $\beta=-2.22$, $95 \% \mathrm{CI},-3.43$ to $-1.01, \mathrm{p}=0.01$ ), $\mathrm{MCH}$ (adjusted $\beta=-0.63,95 \% \mathrm{CI},-1.15$ to $-0.12, \mathrm{p}=0.01)$ and $\mathrm{MCHC}$ (adjusted $\beta=-0.67,95 \% \mathrm{CI},-1.21$ to $-0.14, \mathrm{p}=0.01$ ) respectively (Table 4).

\section{Discussion}

In this population-based birth cohort of young Ethiopian children followed-up to age 6.5 years, we have examined the association between earlier and current $H$. pylori infection and anaemia at age 6.5 years. We found that current $H$. pylori infection at age 6.5 years was positively, though not significantly, related to prevalence of anaemia, while any $H$. pylori infection up to age 6.5 years was significantly associated with an increased odds of anaemia.

The strengths of this study are that the data come from a population based birth cohort with a high response rate and good retention (93\% of surviving mother-child pairs were retained between birth and 6.5 years), thereby minimizing selection bias. We have also used a highly sensitive and specific $H$. pylori stool antigen test [35]. In addition, measurement of the key outcome (anaemia) was done objectively using WHO age-specific haemoglobin cutoffs [32], though identification of anaemia by means of the haemoglobin level may have impaired the detection of iron-deficiency anemia, which might be better detected by measuring serum ferritin and transferrin receptor [36]. This methodological approach however still requires validation in population surveys [37] and in resource limited settings, the prevalence of iron deficiency has often been derived from the prevalence of anaemia using measurements of blood 
Table 2 Haematological parameters mean (standard deviation) and anaemia prevalence at age 06.5 years according to gender of child, Butajira birth cohort study, Ethiopia. $\mathrm{N}=739$

\begin{tabular}{|c|c|c|c|c|c|}
\hline Variables & $\begin{array}{l}\text { Overall } \\
(\mathrm{N}=739)\end{array}$ & $\begin{array}{l}\text { Female } \\
\mathrm{N}=361\end{array}$ & $\begin{array}{l}\text { Male } \\
(\mathrm{N}=378)\end{array}$ & $\begin{array}{l}\text { Mean difference/Crud OR } \\
(95 \% \mathrm{Cl})\end{array}$ & $p$ value \\
\hline $\mathrm{Hgb}(\mathrm{gm} / \mathrm{dl})$ & $11.8(1.1)$ & $11.8(1.08)$ & $11.7(1.15)$ & $0.12(-0.04-0.28)^{a}$ & 0.14 \\
\hline $\mathrm{RBC}\left(\times 10^{12} / \mathrm{L}\right)$ & $4.5(0.37)$ & $4.51(0.35)$ & $4.52(0.37)$ & $0.12(-0.04-0.06)^{a}$ & 0.66 \\
\hline $\mathrm{MCH}(\mathrm{pg})$ & $26.1(2.2)$ & $26.2(2.16)$ & $26.1(2.24)$ & $0.13(-0.19-0.45)^{a}$ & 0.43 \\
\hline $\mathrm{MCHC}(\mathrm{gm} / \mathrm{dl})$ & $31.6(1.5)$ & $31.8(1.35)$ & $31.7(1.56)$ & $0.02(-0.18-0.23)^{a}$ & 0.82 \\
\hline MCV (fl) & $81.1(4.8)$ & $81.3(4.69)$ & $81.0(4.82)$ & $0.40(-0.28-1.09)^{a}$ & 0.25 \\
\hline Anaemia prevalence ${ }^{*} \mathrm{n}(\%)$ & 257 (34.8) & $119(33.0)$ & 138 (36.5) & $0.85(0.63-1.15)^{\mathrm{b}}$ & 0.31 \\
\hline
\end{tabular}

${ }^{¥}$ Anaemia was defined according to WHO haemoglobin cut-offs: $<11.5 \mathrm{~g} / \mathrm{dL}$ for children $5-11$ years

${ }^{a}$ Mean difference and $95 \% \mathrm{Cl}$ mean difference was calculated using the independent $\mathrm{t}$ test

${ }^{\mathrm{b}}$ Crude Odds ratio (OR) and $95 \% \mathrm{Cl}$ OR was calculated using binary logistic regression

haemoglobin [38-40], and red cell indices [41]. Our data showed a significant reduction of $\mathrm{Hb}, \mathrm{MCV}$ and $\mathrm{MCH}$ among children who had any $H$. pylori infection up to age 6.5, which provide, in part, an indication that irondeficiency as a plausible origin for the observed anemia. Although other iron-related tests are required for the confirmation of iron deficiency, it is reasonable to assume that a population with a high anemia prevalence is likely to also have a high prevalence of iron deficiency [38, 40]. Furthermore, hereditary hemoglobinopathies are uncommon in Ethiopia [42], so bias relating to either missing or misclassifying the other forms of anaemia in our study population is unlikely to be a serious concern.

The decrease prevalence of $H$. pylori infection in our study population (10.4\%) of six and half year old children, can be contrasted with the previous reports of $41 \%$ at age three [27] and $44 \%$ at age five [29] in the same cohort.
However, a similar pattern of $H$. pylori prevalence was reported in previous cohort study in Butajira, where the peak age for H. Pylori infection was reported below 6 year, and patterns of repeated seroconversion and seroreversion are restricted in early childhood [24]. Another cohort study among children from high income country also reported a decreased prevalence of $H$. pylori infection in older children from $13.6 \%$ at age 18 and 24 months to only $3 \%$ at age 11 years [43]. The authors suggested that infection with $H$. pylori occurred at an early age and spontaneously cleared later [43].

The decline in prevalence of $H$. pylori at age 6.5 in this study may be due to spontaneous elimination of the bacterium [43], or better attention to health issues in older children, or use of antibiotics for other common diseases [44]. Another explanation of this finding could be an increasing antibody production with increasing age that

Table 3 Associations between anaemia at age 6.5 years and $H$. pylori infection at the age of three, 5, and 6.5 years, Butajira birth cohort study, Ethiopia

\begin{tabular}{|c|c|c|c|c|c|c|c|}
\hline \multirow[b]{2}{*}{ Variables } & \multicolumn{7}{|c|}{ Anaemia at age 6.5 years $^{\mathrm{a}}$} \\
\hline & $\bar{N}$ & $\begin{array}{l}\text { Yes } \\
\text { N (\%) }\end{array}$ & $\begin{array}{l}\text { No } \\
\mathrm{N}(\%)\end{array}$ & $\begin{array}{l}\text { Crude OR } \\
(95 \% \mathrm{Cl})\end{array}$ & P-value & $\begin{array}{l}\text { Adjusted OR }{ }^{c} \\
(95 \% \mathrm{Cl})\end{array}$ & P-value \\
\hline \multicolumn{8}{|l|}{ Exposure to $H$. pylori at age 3} \\
\hline No & 300 & $102(34.0)$ & $198(66.0)$ & 1 & & 1 & \\
\hline Yes & 212 & $77(36.3)$ & $135(67.7)$ & $1.12(0.76-1.60)$ & 0.58 & $1.16(0.79-1.71)$ & 0.44 \\
\hline \multicolumn{8}{|l|}{ Exposure to $H$. pylori at age 5} \\
\hline No & 406 & $124(30.5)$ & $282(69.5)$ & 1 & & 1 & \\
\hline Yes & 323 & $128(39.6)$ & $195(60.4)$ & $1.49(1.09-2.02)$ & 0.01 & $1.52(1.11-2.08)$ & 0.01 \\
\hline \multicolumn{8}{|l|}{ Exposure to $H$. pylori at age 6.5} \\
\hline No & 666 & $230(34.5)$ & $436(65.5)$ & 1 & & 1 & \\
\hline Yes & 73 & $27(37.0)$ & $46(63.0)$ & $1.11(0.67-1.83)$ & 0.67 & $1.15(0.69-1.93)$ & 0.59 \\
\hline \multicolumn{8}{|l|}{ Exposure to $H$. pylori up to age $6.5^{\mathrm{b}}$} \\
\hline Never infected & 309 & $88(28.5)$ & $221(71.5)$ & 1 & & 1 & \\
\hline Infected at any age up to age 6.5 & 430 & $169(39.3)$ & $261(60.7)$ & $1.62(1.19-2.23)$ & 0.01 & $1.68(1.22-2.32)$ & 0.01 \\
\hline
\end{tabular}


Table 4 Multivariate generalized linear model of haematological parameters at age 6.5 years in association with Helicobacter pylori infection from 3 to 6.5 years of age, Butajira birth cohort study, Ethiopia

\begin{tabular}{|c|c|c|c|c|c|c|c|c|c|c|c|c|c|c|c|}
\hline \multirow[b]{2}{*}{ Variables } & \multicolumn{3}{|l|}{$\mathrm{Hb}$} & \multicolumn{3}{|l|}{ RBC } & \multicolumn{3}{|l|}{ MCV } & \multicolumn{3}{|l|}{$\mathrm{MCH}$} & \multicolumn{3}{|l|}{$\mathrm{MCHC}$} \\
\hline & $\overline{\beta^{a}}$ & $95 \% \mathrm{Cl}$ & $P$ & $\overline{\beta^{a}}$ & $95 \% \mathrm{Cl}$ & $P$ & $\overline{\beta^{a}}$ & $95 \% \mathrm{Cl}$ & $P$ & $\overline{\beta^{a}}$ & $95 \% \mathrm{Cl}$ & $P$ & $\overline{\beta^{a}}$ & $95 \% \mathrm{Cl}$ & $P$ \\
\hline \multicolumn{16}{|l|}{ Exposure to $H$. pylori at age 3} \\
\hline Yes & 0.07 & 0.27 to -0.15 & 0.49 & 0.02 & -0.04 to 0.08 & 0.45 & -0.47 & -1.36 to 0.43 & 0.30 & -0.04 & -0.45 to 0.37 & 0.85 & -0.13 & -0.40 to 0.14 & 0.33 \\
\hline No & $0^{\mathrm{b}}$ & & & $0^{\mathrm{b}}$ & & & $0^{\mathrm{b}}$ & & & $0^{\mathrm{b}}$ & & & $0^{\mathrm{b}}$ & & \\
\hline \multicolumn{16}{|l|}{ Exposure to $H$. pylori at age 5} \\
\hline Yes & -0.20 & -0.37 to -0.04 & 0.01 & -0.02 & -0.07 to -0.03 & 0.44 & -0.25 & -0.97 to 0.46 & 0.48 & -0.26 & -0.59 to 0.07 & 0.12 & -0.12 & -0.33 to 0.10 & 0.29 \\
\hline No & $0^{\mathrm{b}}$ & & & $0^{\mathrm{b}}$ & & & $0^{\mathrm{b}}$ & & & $0^{\mathrm{b}}$ & & & $0^{\mathrm{b}}$ & & \\
\hline \multicolumn{16}{|l|}{ Exposure to $H$. pylori at age 6.5} \\
\hline Yes & -0.08 & -0.34 to 0.17 & 0.52 & -0.03 & -0.12 to 0.56 & 0.49 & -0.04 & -1.22 to 1.14 & 0.94 & 0.23 & -0.32 to 0.78 & 0.41 & -0.06 & -0.42 to 0.29 & 0.73 \\
\hline No & $0^{\mathrm{b}}$ & & & $0^{\mathrm{b}}$ & & & $0^{b}$ & & & $0^{b}$ & & & $0^{\mathrm{b}}$ & & \\
\hline \multicolumn{16}{|l|}{ Exposure to $H$. pylori up to age 6.5} \\
\hline Infected at any age up to age 6.5 & -0.19 & -0.35 to -0.03 & 0.01 & -0.06 & -0.15 to 0.02 & 0.11 & -2.22 & -3.43 to -1.01 & 0.01 & -0.63 & -1.15 to -0.12 & 0.01 & -0.67 & -1.21 to -0.14 & 0.01 \\
\hline Never infected & $0^{b}$ & & & $0^{b}$ & & & $0^{b}$ & & & $0^{b}$ & & & $0^{\mathrm{b}}$ & & \\
\hline
\end{tabular}

${ }^{a}$ Changes for haematological parameters at age 6.5 years by Helicobacter pylori infection status from 3 to 6.5 years of age, adjusted for child's gender, area of residence, maternal education, history of vaccination at 2 months, source of water, child's height and weight at 6.5 years

${ }^{\mathrm{b}}$ Reference group 
may lead to the decline of the prevalence rate in older children [45].

The results of this study should be interpreted with caution because the study was conducted in Ethiopia, a low income country in which the causes of anaemia are multi-factorial. Demographic variables and markers of socio-economic status have commonly been found to be associated with anaemia [33, 46, 47]. We therefore measured and controlled for markers of socio-economic status, demographic and lifestyle variables, and found no evidence of confounding by markers of socioeconomic status (urban or rural residence, maternal education, maternal occupation, sanitary condition, source of water or crowdedness), demographic or lifestyle variables (sex, birth weight, history of vaccination at 2 months and 1 year, or vitamin A supplementation at 1 year), which suggest that the effects seen are unlikely to be caused by residual confounding by markers of socio-economic status, demographic and lifestyle variables.

Parasitic diseases causing anaemia are common in Ethiopia, with a recent survey reporting $7.9 \%$ to $34.6 \%$ of school-aged children infected with soil-transmitted helminths, $2.9 \%$ with schistosomiasis and $0.6 \%$ with malaria, respectively $[48,49]$. However, we found no evidence that intestinal parasite infections were contributing to the anaemia we observed at age 6.5.

Infection with malaria parasites has also been associated with anaemia in Ethiopia [33, 47], but our analysis lacked data on status of malaria infection. Studies in the Butajira area of southern Ethiopia have previously shown that malaria transmission is very low. A large population based longitudinal study documented a very low prevalence of malaria $0.93 \%$ (178 malaria cases among 19,207 people) during the peak season for malaria transmission in the area [28]. Another large longitudinal study also documented a very low prevalence of malaria $(1.5 \%(16 / 1080))$, with $0 \%$ during December [50]. This suggests that malaria is unlikely to be a source of bias. However, the observed association between $H$. pylori infection and anemia in this study might not be the same in areas where malaria transmission is high. Further study should be done at high malaria burden settings.

Poor nutrition can cause iron deficiency and potentially increase susceptibility to $H$. pylori infection. However, the consistent effect estimates observed for the different outcomes (anaemia, haemoglobin level and red cell indices) suggest that the findings did not result from residual confounding by malnutrition, or failure to adjust for other potential confounders.

The significant association between any $H$. pylori infection at any age up to 6.5 years and anaemia in the current study is backed by previous epidemiological studies in different settings [51, 52]. A study among Arab children (age 6-9) in Israel reported a 2.8-fold higher risk of anaemia in $H$. pylori infected children compared with uninfected children, after controlling for socioeconomic confounders [51]. Our findings are also consistent with data reported by Baggett et al. [52] from rural Alaska who found a 4.1-fold higher risk of anaemia (AOR: $4.1 ; 95 \% \mathrm{CI}, 0.92$ to $8.0 ; p=0.06$ ) in children (mean age 9.5 years) infected with $H$. pylori. Another study in the United States by Cardenas et al. [53] used data from the 1999-2000 National Health and Nutrition Examination Survey (NHANES), with 7,462 individuals aged $\geq 3$ years. This reported a significant association between sero-positivity for $H$. pylori and iron deficiency anaemia $(\mathrm{OR}=2.6 ; 95 \% \mathrm{CI}: 1.5$ to 4.6$)$ and other types of anaemia $(\mathrm{OR}=1.3 ; 95 \% \mathrm{CI}: 1.0$ to 1.7$)$. The difference in size of the ORs may be due to variation in age, outcome ascertainment, and differences in measurement of infection status.

In this study, the exposure variable representing current $H$. pylori infection (positive for stool antigen test) at age 6.5 was not significantly related to prevalence of anemia. Other studies have also shown no associations between acute/current $H$. pylori infection and childhood anaemia $[54,55]$. The lack of association between acute H. pylori infection and anaemia has been speculated to relate to different stages or expressions of $H$. pylori infection [54]. For instance, current/acute H. pylori infection assessed with stool antigen test [35] may reflect initial H. pylori acquisition, before the establishment of the bacteria, the development of the subsequent immune response, and any effects on the child's haematopoetic system. The bacteria may exist transiently for some time in the stomach of children before persistent colonization and becoming an established infection affecting iron metabolism and causing anemia [54]. It is possible that children positive for stool antigen at age 6.5 years in the study may have been exposed to $H$. pylori for only a short time, so iron stores and haemoglobin synthesis are not yet affected. In contrast to this hypothesis, however, Queiroz et al. [56] suggested that initial colonisation of H. pylori could provoke a stronger inflammatory response, which in turn inhibits iron absorption. This earlier study, unlike the current one, was done among symptomatic children who underwent upper gastrointestinal endoscopy, and may account for higher inflammatory responses. Our study population was distinctly different as all our participants were apparently healthy children, and the former hypothesis seems more likely to fit with our observations.

We have also explored the association between H. pylori infection and haemoglobin levels and red cell indices at age 6.5 years and found a significant reduction of haemoglobin concentration (adjusted $\beta=-0.19 \mathrm{gm} / \mathrm{dl}$, $95 \%$ CI, -0.35 to $-0.03, \mathrm{p}=0.01$ ) among children infected to H. pylori at any age up to 6.5 years. This finding also fit 
with previous studies by both Muhsen et al. [51] and Queiroz et al. [57], who report a significant reduction in haemoglobin level among $H$. pylori infected children, respectively. Similar to the trend seen for haemoglobin, significant reductions in $\mathrm{MCV}, \mathrm{MCH}$ and $\mathrm{MCHC}$ were observed in $H$. pylori infected subjects, which may indicate anaemia from iron deficiency. A large household controlled therapeutic trial among children with iron deficiency aged 7-11 years showed that anti-H. pylori therapy reduced the prevalence of iron deficiency anaemia substantially, and reduced iron deficiency more modestly 40 months after treatment initiation, suggesting that $H$. pylori may play a causal role in haematological outcomes [58].

Several logical mechanisms of association between anaemia and $H$. pylori infection have been suggested. Studies have shown that the $H$. pylori colonization is associated with reduction in iron absorption due to low levels of gastric acid [21], effects on iron transporter molecules [22], blood loss due to H. pylori-induced gastritis or duodenitis [59] and sequestration of dietary iron by $H$. pylori residing in the gastric mucosa [60]. Increased hepcidin production from hepatocytes in response to interleukin-6 ( IL-6) production in H. pylori gastritis has also been proposed as possible mechanism to explain H. pylori associated IDA [23], as this prevents the release of iron from stores in enterocytes.

\section{Conclusions}

In conclusion, our findings indicate that any previous $H$. pylori infection is associated with higher prevalence of anaemia and reduction of haemoglobin level and red cell indices in school-age children, independent of socioeconomic variables. However, current $H$. pylori infection was not significantly associated with increased prevalence of anaemia. Further investigation of the natural history of $H$. pylori infection will be crucial to understanding its manifestations in young children from developing countries, and to develop treatment guideline for $H$. pylori infected children with unexplained anaemia.

\section{Additional files}

Additional file 1: Table S1. Correlates of Helicobacter pylori infection and Anaemia among children aged 6.5 years, Butajira Birth Cohort, Ethiopia.

Additional file 2: Table S3. Comparison of the distribution of demographic and lifestyle characteristics in "Case-complete" and "All respondents" childern at 6.5 year follow-up visit, Butajira Birth Cohort, Ethiopia.

Additional file 3: Table S2. Haematological Parameters Mean (Standard deviation) and Anaemia Prevalence at Age 6.5 Years According to Child's H. pylori infection status from 3 to 6.5 Years of Age, Butajira Birth Cohort Study, Ethiopia.

\section{Competing interests}

The authors declare that they have no competing interests.

\section{Authors' contributions}

BT conceived and designed the study and collected data in the field and performed data analysis, and drafted the manuscript. AA and GM participated in data collection, assisted with the design, performed analysis, interpretation of data and the critical review of the manuscript. GD, FE, AT, KR and AF participated in study design and interpretation of data, helped in drafting the manuscript and critically reviewed the manuscript. All authors read and approved the final manuscript.

\section{Acknowledgments}

We gratefully thank the mothers and children in the birth cohort who generously provided information, and the project data collectors and the laboratory technicians for their commitment during the field work. The study was supported by the National Institute for Health Research (NIHR), through the NIHR Biomedical Research Unit in Gastrointestinal and Liver Diseases at Nottingham University Hospitals NHS Trust and the University of Nottingham. The views expressed are those of the author(s) and not necessarily those of the NHS, the NIHR or the Department of Health.

\section{Author details}

${ }^{1}$ School of Public Health, College of Health Sciences, Addis Ababa University, PO Box 80596, Addis Ababa, Ethiopia. ${ }^{2}$ School of Allied Health Sciences, College of Health Sciences, Addis Ababa University, Addis Ababa, Ethiopia. ${ }^{3}$ Department of Infectious Disease Epidemiology, London School of Hygiene and Tropical Medicine, Nottingham, UK. ${ }^{4}$ Aklilu Lemma Institute of Pathobiology, Addis Ababa University, Addis Ababa, Ethiopia. ${ }^{5}$ Division of Epidemiology and Public Health, University of Nottingham, Nottingham, UK. ${ }^{6}$ Nottingham Digestive Diseases Biomedical Research Unit, School of Medicine, University of Nottingham, Nottingham, UK. ${ }^{7}$ Brighton \& Sussex Medical School, Nottingham, UK.

Received: 5 March 2015 Accepted: 6 July 2015

Published online: 14 July 2015

\section{References}

1. Marshall BJ, Warren JR. Unidentified curved bacilli in the stomach of patients with gastritis and peptic ulceration. Lancet. 1984;1(8390):1311-5.

2. Mitchell HM. The epidemiology of Helicobacter pylori. Curr Top Microbiol Immunol. 1999:241:11-30.

3. Suerbaum S, Michetti P. Helicobacter pylori infection. N Engl J Med. 2002;347(15):1175-86.

4. Ernst PB, Gold BD. The disease spectrum of Helicobacter pylori: the immunopathogenesis of gastroduodenal ulcer and gastric cancer. Annu Rev Microbiol. 2000;54:615-40.

5. Banatvala N, Mayo K, Megraud F, Jennings R, Deeks JJ, Feldman RA. The cohort effect and Helicobacter pylori. J Infect Dis. 1993;168(1):219-21.

6. Blaser MJ, Atherton JC. Helicobacter pylori persistence: biology and disease. J Clin Invest. 2004;113(3):321-33.

7. Macarthur C, Saunders N, Feldman W, Ipp M, Winders-Lee P, Roberts S, et al. Helicobacter pylori and childhood recurrent abdominal pain: community based case-control study. Bmj. 1999;319(7213):822-3.

8. Torres J, Perez-Perez G, Goodman KJ, Atherton JC, Gold BD, Harris PR, et al. A comprehensive review of the natural history of Helicobacter pylori infection in children. Arch Med Res. 2000;31(5):431-69.

9. Rowland M, Imrie C, Bourke B, Drumm B. How should Helicobacter pylori infected children be managed? Gut. 1999;45(1):136-9.

10. Drumm B, Rhoads JM, Stringer DA, Sherman PM, Ellis LE, Durie PR. Peptic ulcer disease in children: etiology, clinical findings, and clinical course. Pediatrics. 1988;82(3 Pt 2):410-4.

11. Figura N, Franceschi F, Santucci A, Bernardini G, Gasbarrini G, Gasbarrini A. Extragastric manifestations of Helicobacter pylori infection. Helicobacter. 2010;1:60-8

12. Ashorn M, Ruuska T, Makipernaa A. Helicobacter pylori and iron deficiency anaemia in children. Scand J Gastroenterol. 2001;36(7):701-5.

13. Barabino A, Dufour C, Marino CE, Claudiani F, De Alessandri A. Unexplained refractory iron-deficiency anemia associated with Helicobacter pylori gastric infection in children: further clinical evidence. J Pediatr Gastroenterol Nutr. 1999;28(1):116-9.

14. Choe YH, Kim SK, Hong YC. Helicobacter pylori infection with iron deficiency anaemia and subnormal growth at puberty. Arch Dis Child. 2000;82(2):136-40. 
15. Qu XH, Huang XL, Xiong P, Zhu CY, Huang YL, Lu LG, et al. Does Helicobacter pylori infection play a role in iron deficiency anemia? A metaanalysis. World J Gastroenterol. 2010;16(7):886-96.

16. Choe YH, Kim SK, Son BK, Lee DH, Hong YC, Pai SH. Randomized placebocontrolled trial of Helicobacter pylori eradication for iron-deficiency anemia in preadolescent children and adolescents. Helicobacter. 1999;4(2):135-9.

17. Konno M, Muraoka S, Takahashi M, Imai T. Iron-deficiency anemia associated with Helicobacter pylori gastritis. J Pediatr Gastroenterol Nutr. 2000;31(1):52-6.

18. Choe YH, Kwon YS, Jung MK, Kang SK, Hwang TS, Hong YC. Helicobacter pylori-associated iron-deficiency anemia in adolescent female athletes. J Pediatr. 2001;139(1):100-4.

19. Pacifico L, Anania C, Osborn JF, Ferraro F, Chiesa C. Consequences of Helicobacter pylori infection in children. World J Gastroenterol. 2010;16(41):5181-94.

20. DuBois S, Kearney DJ. Iron-deficiency anemia and Helicobacter pylori infection: a review of the evidence. Am J Gastroenterol. 2005;100(2):453-9.

21. Capurso G, Lahner E, Marcheggiano A, Caruana P, Carnuccio A, Bordi C, et al. Involvement of the corporal mucosa and related changes in gastric acid secretion characterize patients with iron deficiency anaemia associated with Helicobacter pylori infection. Aliment Pharmacol Ther. 2001;15(11):1753-61.

22. Choe YH, Oh YJ, Lee NG, Imoto I, Adachi Y, Toyoda N, et al. Lactoferrin sequestration and its contribution to iron-deficiency anemia in Helicobacter pylori-infected gastric mucosa. J Gastroenterol Hepatol. 2003;18(8):980-5.

23. Pellicano R, Rizzetto M. Is hepcidin the bridge linking Helicobacter pylori and anemia of chronic infection? A research proposal. Panminerva Med. 2004;46(3):165-9.

24. Lindkvist P, Enquselassie F, Asrat D, Nilsson I, Muhe L, Giesecke J. Helicobacter pylori infection in Ethiopian children: a cohort study. Scand J Infect Dis. 1999:31(5):475-80.

25. Megraud F, Brassens-Rabbe MP, Denis F, Belbouri A, Hoa DQ. Seroepidemiology of Campylobacter pylori infection in various populations. J Clin Microbiol. 1989;27(8):1870-3.

26. Tolentino K, Friedman JF. An update on anemia in less developed countries. Am J Trop Med Hyg. 2007;77(1):44-51.

27. Amberbir A, Medhin G, Erku W, Alem A, Simms R, Robinson K, et al. Effects of Helicobacter pylori, geohelminth infection and selected commensal bacteria on the risk of allergic disease and sensitization in 3-year-old Ethiopian children. Clin Exp Allergy. 2011:41(10):1422-30.

28. Woyessa A, Deressa W, Ali A, Lindtjorn B. Prevalence of malaria infection in Butajira area, south-central Ethiopia. Malar J. 2012;11(84):1475-2875.

29. Amberbir A, Medhin G, Abegaz WE, Hanlon C, Robinson K, Fogarty A, et al. Exposure to Helicobacter pylori infection in early childhood and the risk of allergic disease and atopic sensitization: a longitudinal birth cohort study. Clin Exp Allergy. 2014;44(4):563-71.

30. Hanlon C, Medhin G, Alem A, Tesfaye F, Lakew Z, Worku B, et al. Impact of antenatal common mental disorders upon perinatal outcomes in Ethiopia: the P-MaMiE population-based cohort study. Trop Med Int Health. 2009;14(2):156-66.

31. Medhin G, Hanlon C, Dewey M, Alem A, Tesfaye F, Worku B, et al. Prevalence and predictors of undernutrition among infants aged six and twelve months in Butajira, Ethiopia: the P-MaMiE Birth Cohort. BMC Public Health. 2010;10(27):1471-2458.

32. World Health Organization. Iron Deficiency Anaemia: As -sessment, Prevention and Control. A Guide for Programme Managers. Geneva, Switzerland: World Health Organization; 2001.

33. Reithinger R, Ngondi JM, Graves PM, Hwang J, Getachew A, Jima D. Risk factors for anemia in children under 6 years of age in Ethiopia: analysis of the data from the cross-sectional Malaria IndicatorSurvey, 2007. Trans R Soc Trop Med Hyg. 2013;107(12):769-76.

34. Vrieze SI. Model selection and psychological theory: a discussion of the differences between the Akaike information criterion (AIC) and the Bayesian information criterion (BIC). Psychol Methods. 2012;17(2):228-43.

35. Vaira D, Malfertheiner P, Megraud F, Axon AT, Deltenre M, Hirschl AM, et al. Diagnosis of Helicobacter pylori infection with a new non-invasive antigen-based assay. HpSA European study group. Lancet. 1999:354(9172):30-3.

36. Jain S, Narayan S, Chandra J, Sharma S, Malhan P. Evaluation of serum transferrin receptor and sTfR ferritin indices in diagnosing and differentiating iron deficiency anemia from anemia of chronic disease. Indian J Pediatr. 2010;77(2):179-83.
37. Joint World Health Organization/Centers for Disease C, Prevention Technical Consultation on the Assessment of Iron Status at the Population Level WHONfH, Development CfDC, Prevention DoN, Physical Activity IMMP, Control P, editors. Assessing the iron status of populations: report of a Joint World Health Organization/Centers for Disease Control and Prevention Technical Consultation on the Assessment of Iron Status at the Population Level, Geneva, Switzerland, 6-8 April 2004. Geneva; [Atlanta, Ga.]: World Health Organization, Dept. of Nutrition for Health and Development; Centers for Disease Control and Prevention, Division of Nutrition and Physical Activity, International Micronutrient Malnutrition Prevention and Control Program; 2005.

38. Yip R. Iron deficiency: contemporary scientific issues and international programmatic approaches. J Nutr. 1994;124(8 Suppl):1479S-90.

39. Khusun H, Yip R, Schultink W, Dillon DH. World Health Organization hemoglobin cut-off points for the detection of anemia are valid for an Indonesian population. J Nutr. 1999;129(9):1669-74.

40. Freire WB. Hemoglobin as a predictor of response to iron therapy and its use in screening and prevalence estimates. Am J Clin Nutr. 1989;50(6):1442-9.

41. Dugdale AE. Predicting iron and folate deficiency anaemias from standard blood testing: the mechanism and implications for clinical medicine and public health in developing countries. Theor Biol Med Model. 2006;3:34.

42. Williams TN, Weatherall DJ. World distribution, population genetics, and health burden of the hemoglobinopathies. Cold Spring Harb Perspect Med. 2012;2:a011692.

43. Granstrom M, Tindberg Y, Blennow M. Seroepidemiology of Helicobacter pylori infection in a cohort of children monitored from 6 months to 11 years of age. J Clin Microbiol. 1997;35(2):468-70.

44. Broussard CS, Goodman KJ, Phillips CV, Smith MA, Fischbach LA, Day RS, et al. Antibiotics taken for other illnesses and spontaneous clearance of Helicobacter pylori infection in children. Pharmacoepidemiol Drug Saf. 2009;18(8):722-9.

45. Rothenbacher D, Bode G, Brenner H. Dynamics of Helicobacter pylori infection in early childhood in a high-risk group living in Germany: loss of infection higher than acquisition. Aliment Pharmacol Ther. 2002;16(9):1663-8.

46. Pasricha SR, Black J, Muthayya S, Shet A, Bhat V, Nagaraj S, et al. Determinants of anemia among young children in rural India. Pediatrics. 2010;126(1):2009-3108.

47. Muhe L, Oljira B, Degefu H, Jaffar S, Weber MW. Evaluation of clinical pallor in the identification and treatment of children with moderate and severe anaemia. Trop Med Int Health. 2000;5(11):805-10.

48. King JD, Endeshaw T, Escher E, Alemtaye G, Melaku S, Gelaye W, et al. Intestinal parasite prevalence in an area of ethiopia after implementing the SAFE strategy, enhanced outreach services, and health extension program. PLoS Negl Trop Dis. 2013;7(6):e2223. doi:10.1371/journal.pntd.0002223.

49. Ashton RA, Kefyalew T, Tesfaye G, Pullan RL, Yadeta D, Reithinger R, et al. School-based surveys of malaria in Oromia Regional State, Ethiopia: a rapid survey method for malaria in low transmission settings. Malar J. 2011;10(1):1475-2875.

50. Tesfaye S, Belyhun Y, Teklu T, Mengesha T, Petros B. Malaria prevalence pattern observed in the highland fringe of Butajira, Southern Ethiopia: a longitudinal study from parasitological and entomological survey. Malar J. 2011;10(153):1475-2875.

51. Muhsen K, Barak M, Henig C, Alpert G, Ornoy A, Cohen D. Is the association between Helicobacter pylori infection and anemia age dependent? Helicobacter. 2010;15(5):467-72.

52. Baggett HC, Parkinson AJ, Muth PT, Gold BD, Gessner BD. Endemic iron deficiency associated with Helicobacter pylori infection among school-aged children in Alaska. Pediatrics. 2006;117(3):1.

53. Cardenas VM, Mulla ZD, Ortiz M, Graham DY. Iron deficiency and Helicobacter pylori infection in the United States. Am J Epidemiol. 2006;163(2):127-34.

54. DiGirolamo AM, Perry GS, Gold BD, Parkinson A, Provost EM, Parvanta I, et al. Helicobacter pylori, anemia, and iron deficiency: relationships explored among Alaska native children. Pediatr Infect Dis J. 2007;26(10):927-34.

55. Haghi-Ashtiani MT, Monajemzadeh M, Motamed F, Mahjoub F, Sharifan M, Shahsiah $\mathrm{R}$, et al. Anemia in children with and without Helicobacter pylori infection. Arch Med Res. 2008;39(5):536-40.

56. Queiroz DM, Rocha AM, Melo FF, Rocha GA, Teixeira KN, Carvalho SD, et al. Increased gastric IL-1beta concentration and iron deficiency parameters in H. pylori infected children. PLoS One. 2013;8(2):25. 
57. Queiroz DM, Harris PR, Sanderson IR, Windle HJ, Walker MM, Rocha AM, et al. Iron status and Helicobacter pylori infection in symptomatic children: an international multi-centered study. PLoS One. 2013;8(7):e68833. doi:10.1371/journal.pone.0068833.

58. Fagan RP, Dunaway CE, Bruden DL, Parkinson AJ, Gessner BD. Controlled, household-randomized, open-label trial of the effect of treatment of Helicobacter pylori infection on iron deficiency among children in rural Alaska: results at 40 months. J Infect Dis. 2009:199(5):652-60.

59. Yip R, Limburg PJ, Ahlquist DA, Carpenter HA, O'Neill A, Kruse D, et al. Pervasive occult gastrointestinal bleeding in an Alaska native population with prevalent iron deficiency. Role of Helicobacter pylori gastritis. Jama. 1997;277(14):1135-9.

60. Barabino A. Helicobacter pylori-related iron deficiency anemia: a review. Helicobacter. 2002;7(2):71-5.

\section{Submit your next manuscript to BioMed Central and take full advantage of:}

- Convenient online submission

- Thorough peer review

- No space constraints or color figure charges

- Immediate publication on acceptance

- Inclusion in PubMed, CAS, Scopus and Google Scholar

- Research which is freely available for redistribution 